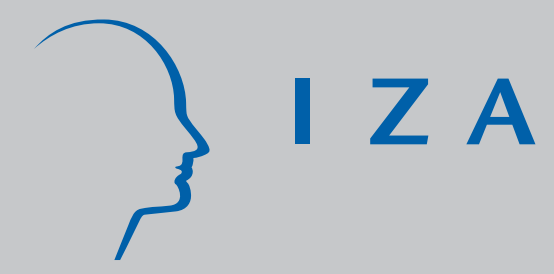

IZA DP No. 3566

Outsourcing of Unionized Firms and the Impact of Labor Market Policy Reforms

Erkki Koskela

Ronnie Schöb

J une 2008 


\title{
Outsourcing of Unionized Firms and the Impact of Labor Market Policy Reforms
}

\author{
Erkki Koskela \\ University of Helsinki \\ and IZA
}

Ronnie Schöb

Free University of Berlin

\section{Discussion Paper No. 3566}

June 2008

IZA

P.O. Box 7240

53072 Bonn

Germany

Phone: +49-228-3894-0

Fax: +49-228-3894-180

E-mail: iza@iza.org

Any opinions expressed here are those of the author(s) and not those of IZA. Research published in this series may include views on policy, but the institute itself takes no institutional policy positions.

The Institute for the Study of Labor (IZA) in Bonn is a local and virtual international research center and a place of communication between science, politics and business. IZA is an independent nonprofit organization supported by Deutsche Post World Net. The center is associated with the University of Bonn and offers a stimulating research environment through its international network, workshops and conferences, data service, project support, research visits and doctoral program. IZA engages in (i) original and internationally competitive research in all fields of labor economics, (ii) development of policy concepts, and (iii) dissemination of research results and concepts to the interested public.

IZA Discussion Papers often represent preliminary work and are circulated to encourage discussion. Citation of such a paper should account for its provisional character. A revised version may be available directly from the author. 


\section{ABSTRACT \\ Outsourcing of Unionized Firms and the Impact of Labor Market Policy Reforms*}

This paper shows that outsourcing of parts of workforce in unionized firms leads to wage moderation both in the case of strategic and flexible outsourcing and as long as the share of the outsourced workforce is not too large, this wage-moderation effect on domestic employment outweighs the direct substitution effect so that domestic employment increases in unionized firms as outsourcing costs fall. With respect the impact of labor tax reforms that are well-established in the literature: changes in the wage tax rate, the tax exemption and the unemployment benefit payments affect domestic wage setting in the same way as in the absence of outsourcing. Furthermore, increasing the degree of tax progression by keeping the relative tax burden per worker constant continues to be good for employment. However, except for low outsourcing activities, the impact of these policy measures will become smaller as outsourcing costs fall.

JEL Classification: J41, J51, H22

Keywords: $\quad$ outsourcing, union wage-setting, employment, labor tax reform

Corresponding author:

Erkki Koskela

Department of Economics

University of Helsinki

P.O. Box 17 (Arkadiankatu 7)

00014 Helsinki

Finland

E-mail: erkki.koskela@helsinki.fi

Erkki Koskela thanks Freie Universität Berlin for great hospitality and Ronnie Schöb thanks the Research Unit of Economic Structures and Growth (RUESG) for great hospitality. Koskela also thanks the Yrjö Jahnsson Foundation and the Academy of Finland (grant No. 111 7698) for financial support. 


\section{Introduction}

Wage differences constitute a central explanation for the increasing dominant business practice of international outsourcing across a wide range of industries. ${ }^{1}$ In high-wage countries with high unemployment rates due to labor market imperfections there are deep concerns about the adverse consequences of increasing outsourcing activities. Outsourcing, so the argument goes, threatens jobs in the home country because foreign jobs may replace domestic jobs. Indeed, there is a direct crowding out when domestic and foreign jobs are substitutes. ${ }^{2}$ But this may not be the whole story.

When outsourcing and domestic labor are substitutes, the domestic labor demand is decreasing and the wage elasticity of domestic labor demand is increasing in the share of outsourcing (see e.g. Senses (2006) for empirical evidence). This limits the mark-up trade unions can set above the opportunity cost of labor. Our paper shows that this indirect positive wage moderation effect will be stronger than the direct substitution effect as long as outsourcing costs are not yet too low. Then, domestic employment in outsourcing unionized firms increases when economic integration leads to a further fall in outsourcing costs because the ease of outsourcing disciplines the firms' unions.

Both substitution and wage moderation effects affect the efficacy of the government's employment policy measures that aims at correcting the labor market failure. In the second part we analyze the consequences for domestic labor market policies, which, when direct controls are ruled out, are mainly restricted to changes of the labor tax system, by altering labor taxes and workers' tax exemptions, or the social security system, in particular the generosity of the unemployment insurance scheme. For

\footnotetext{
${ }^{1}$ See e.g. Sinn (2007) for an overview or Stefanova (2006) concerning the East-West dichotomy of outsourcing. Amiti and Wei (2005) as well as Rishi and Saxena (2004) emphasize the big difference in labor costs as the main explanation for the strong increase in outsourcing of both manufacturing and services to countries with low labor costs.

${ }^{2}$ Outsourcing may be beneficial for domestic jobs when foreign jobs are complements to domestic jobs. See Skaksen and Sörensen (2001) for a theoretical treatment and e.g. Leahy and Montagna (2000) for empirical evidence.
} 
these policies we will analyze to which extent outsourcing limits the efficacy of labor tax reforms with respect to domestic employment in unionized firms that engage in outsourcing. This policy-relevant issue will be discussed for two different outsourcing scenarios. Firms may write long-term contracts that fix the amount of outsourcing before the trade union sets the wage - which we will call the case of strategic outsourcing - or alternatively, firms may be flexible enough to decide upon the amount of outsourcing activity simultaneously with domestic labor demand after the domestic wage is set by the trade union. We analyze how three isolated labor tax policy changes and one labor tax reform that all have proven as employment enhancing in the absence of outsourcing. ${ }^{3}$ It turns out that, when domestic labor and outsourcing are perfect substitutes, both the negative effects of the wage tax and the generous unemployment benefit payments on domestic labor demand and the positive effect of the tax exemption for workers on labor demand prevail. However, for any given labour demand elasticity the magnitude of changes critically hinges on the share of outsourcing activities. If outsourcing occurs but still plays a minor role for the firm, the effect of domestic labor tax policies on domestic employment in unionized firms becomes stronger than in the absence of outsourcing.

We proceed as follows. Section 2 presents the basic structure of theoretical framework and lays out the time sequences of various decisions on labor demand and wage setting. In section 3 strategic outsourcing is presented and the effects of labor tax instruments and tax reforms are analyzed in section 4. Section 5 then analyzes the case of flexible outsourcing. The analytical results are illustrated by some numerical simulations in section 6. Finally, we present conclusions in section 7.

\section{Basic framework}

We first consider the case where the firm writes a long-term contract that fixes the amount of outsourcing before the trade union sets the wage. At stage 1, the government

\footnotetext{
${ }^{3}$ See, e.g. Koskela and Vilmunen (1996), Koskela and Schöb (1999), (2002a), (2002b).
} 
behaves as a Stackelberg leader and fixes the two labor tax parameters. To raise revenues, the government can employ a wage tax $t$, which is levied on the gross wage $w$, minus a tax exemption $a$. The tax base per worker for the wage tax $t$ thus equals $(w-a)$. In the presence of a positive tax exemption $a$, the marginal tax rate $t$ exceeds the average tax rate $t(1-a / w)$ so that the tax system is linearly progressive. ${ }^{4}$ The net-oftax wage the worker receives is given by $w^{n}=(1-t) w+t a$.

At stage 2, the firm decides about how much of the workforce to outsource. The firm produces an output good with labor only, whereby, for analytical convenience, domestic labor $L$ and foreign labor, i.e. outsourcing, $M$, are assumed to be perfect substitutes. To derive an explicit solution, we postulate the following decreasing returnsto-scale production function in terms:

$$
f(L+M)=\frac{\delta}{\delta-1}(L+M)^{\frac{\delta-1}{\delta}}, \quad \delta>1
$$

The price of the output good is normalized to unity. Profit is given by $\pi=f(L+M)-w L-C(M)$, where $C(M)=0.5 c M^{2}$ is a convex cost of establishing capacity $M$ for foreign outsourced.

At stage 3, the monopolistic firm-level trade union sets the gross wage. ${ }^{5}$ It takes both the tax parameters and the outsourcing decision of the firm as given and anticipates the consequences that the wage setting will have for the domestic labor demand of its firm in stage 4. The time sequence of these decisions is summarized in Figure 1. The decisions at each stage are analyzed by using backward induction. The analysis of the case where domestic labor demand and outsourcing are decided simultaneously is delegated to section 5 .

\footnotetext{
4 For a seminal paper about tax progression, see Musgrave and Thin (1948), and for another elaboration, see e.g. Lambert (2001, chapters 7-8).

5 Since tax parameters are given from the viewpoint of firms and trade unions, it does not matter whether they bargain over gross or net-of-tax wages (see e.g. Koskela and Schöb 2002b).
} 
Figure 1: Time sequence of decisions: strategic outsourcing

\begin{tabular}{c|ccc}
$1^{\text {st }}$ stage & $2^{\text {nd }}$ stage & $3^{\text {rd }}$ stage & $4^{\text {th }}$ stage \\
\hline $\begin{array}{c}\text { Tax policy } \\
(t, a, b)\end{array}$ & Outsourcing $(M)$ & Wage setting $(w)$ & $\begin{array}{c}\text { Domestic } \\
\text { labor demand }(L)\end{array}$
\end{tabular}

\section{$2.14^{\text {th }}$ stage: labour demand}

In the $4^{\text {th }}$ stage, firms hire domestic workers according to the first-order profit maximization condition, which is $\pi_{L}=0=f_{L}(L+M)-w$. Using the production function (1) this leads to

$$
L(w, M)=w^{-\delta}-M
$$

A more extensive outsourcing activity will cet. par. decrease domestic labor demand. This feature is fully consistent with empirical evidence. ${ }^{6}$ Apart from the direct substitution effect $d L=-d M$, there is an additional indirect effect on domestic employment because outsourcing also affects the wage elasticity of labor demand

$$
\eta(M, w, \delta) \equiv-\frac{L_{w} w}{L}=\delta \frac{w^{-\delta}}{L(w, M)}=\delta\left(1+\frac{M}{L(w, M)}\right) \equiv \frac{\delta}{1-\alpha},
$$

where $\alpha=M /(L+M)$ indicates the share of the workforce that is outsourced. In the absence of outsourcing this elasticity is constant, $\left.\eta\right|_{\alpha=0}=\delta$. Domestic labor demand becomes the more elastic the larger the share of outsourcing is, i.e. we have $\eta_{\alpha}=\eta /(1-\alpha)>0 .{ }^{7}$ Furthermore, in the presence of outsourcing, domestic labor demand becomes sensitive to changes in the domestic labor cost, i.e. the gross wage $w$ : the elasticity reacts positively to the wage set by the trade union, i.e. we have (using equation (2)): $\eta_{w}=\eta \frac{\delta M}{w L}>0$.

\footnotetext{
6 See e.g. Görg and Hanley (2005) and Hijzen et al. (2005).

7 Senses (2006) recently provided empirical evidence according to which higher outsourcing increases the wage elasticity of labor demand. See also Hasan et al. (2007) and Slaughter (2001).
} 


\section{$2.23^{\text {rd }}$ stage: wage setting}

Wages are determined by a firm-level monopoly trade union, which maximizes the sum of its $N$ members' income that consists of the net-of-tax wage income of employed member and some unemployment benefit payments $b$ for those being unemployed. We assume that from the viewpoint of a small firm-level trade union $b$ is exogenous. Denoting the objective function of the trade union by $V$, the maximization problem of the trade union is

$$
\underbrace{\max }_{(w)} V=(w(1-t)+t a) L+(N-L) b \quad \text { s.t. } L=w^{-\delta}-M,
$$

from which it is straightforward to calculate the optimal wage

$$
w=\frac{\eta}{(\eta-1)} \frac{(b-t a)}{(1-t)} \equiv \frac{\eta}{(\eta-1)} \hat{b} .
$$

The comparative statics - taking into account that (5) is only an implicit function as we know from substituting in the wage elasticity of labor demand (3) - shows first that outsourcing leads trade unions to moderate wages because the outsourcing activity $M$ positively affects the elasticity of labor demand and thereby negatively the wage rate via the mark-up $\eta /(\eta-1): w_{M}<0$ (see Appendix 1). When the share of outsourcing increases, a wage rise benefits less domestic workers for any given number of wageinduced lay-offs. It is thus beneficial for the trade union to lower the wage when outsourcing has increased exogenously. ${ }^{8}$

The effects of wage tax and tax exemption changes on wage formation are qualitatively the same with and without outsourcing, i.e. we have $w_{t}>0$ and $w_{a}<0$, although the effects are smaller in absolute terms when the firm engages in outsourcing.

\footnotetext{
8 Egger and Egger (2003) study the impact of a decline in trade barriers on outsourcing of low-skilled labor and find empirical evidence that outsourcing decreases wages of low-skilled labor. See also Feenstra and Hanson (1999) and Hijzen et al. (2005).
} 


\section{3. $2^{\text {nd }}$ stage: strategic outsourcing}

In the second stage, the firm maximizes profit with respect to outsourcing activities taking into account its implication on the wage setting of the trade union and the subsequent on decision on domestic labor input. From $\pi=\delta(\delta-1)^{-1}(L+M)^{(\delta-1) / \delta}-w L-0.5 c M^{2}$, we obtain the first-order condition $\pi_{M}=w-w_{M} L-c M=0$ and thus

$$
c M>w .
$$

Since $w_{M}<0$, it becomes profitable for the firm to increase the outsourcing above the level where the marginal outsourcing cost $c M$ equals the domestic gross wage $w$. Higher outsourcing reaps an additional benefit for the firm in forcing its trade union to lower domestic wages. Figure 2 illustrates the reasoning.

Figure 2: Strategic outsourcing in the presence of trade unions

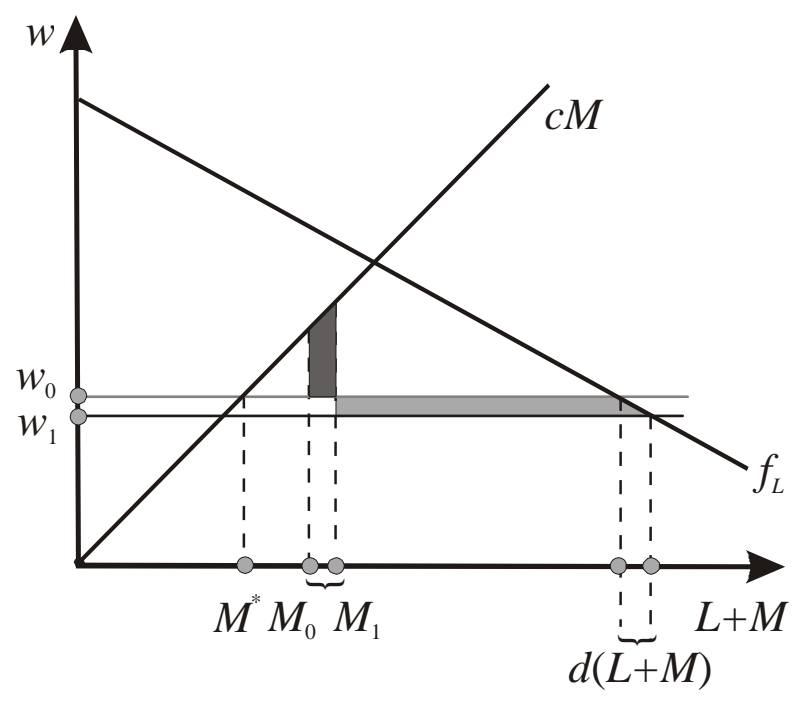

When the firm increases its outsourcing activity from $M_{0}$ to $M_{1}$ in Figure 2, it replaces the same amount of domestic workers at the given initial wage $w_{0}$, and it increases the production cost by the trapezoid shaded in dark grey. Since this leads the trade union to moderate wages in stage 3, it will increase total employment by $d(L+M)$ and save a domestic wage bill equal to the area shaded in light grey. The optimal outsourcing is 
where the two areas are of equal size (for marginal changes). The strategic component of outsourcing in Figure 2 is indicated by $M_{1}-M^{*}$. This result can be presented in

PROPOSITION 1: In the presence of a domestic firm-level trade union, the firm will exceed its strategic outsourcing activity beyond the level where domestic and foreign marginal labor costs are the same.

\section{Increased international integration}

In the following, we are interested in how domestic labor market policies are affected when the possibilities to outsource part of the workforce increase due to increased economic integration that lowers the outsourcing cost parameter $c$. A lower $c$ has a positive effect on outsourcing, $M_{c}<0$, which in turn moderates domestic wages because $d w / d c=w_{M} M_{c}>0$ (see Appendix 1) : a trade union in a firm that can engage in outsourcing will moderate wages to alleviate the consequences of increased economic integration. By contrast, the effect on domestic labor is not as clear-cut as might be expected:

$$
\frac{d L}{d c}=\underbrace{L_{w} \frac{d w}{d c}}_{-}+\underbrace{L_{M}}_{-1} \underbrace{M_{c}}_{-}=-M_{c}\left[1-L_{w} w_{M}\right]\left\{\begin{array}{l}
> \\
= \\
<
\end{array}\right\} \text { as } \alpha\left\{\begin{array}{l}
> \\
= \\
<
\end{array}\right\} \frac{1}{\delta+1},
$$

where

$$
1-L_{w} w_{M}=1+\frac{L_{w} w}{[(\delta-1) L+2 \delta M]}=1-\frac{\delta(L+M)}{[(\delta-1) L+2 \delta M]}=\frac{\alpha(\delta+1)-1}{\alpha(\delta+1)-1+\delta}
$$

When $c$ falls, we have the direct effect of substituting foreign labor for domestic labor. This effect is counteracted by the indirect wage moderating effect. As it turns out, the indirect effect may be stronger as long as the share of outsourcing is small in the sense that $\alpha<(\delta+1)^{-1}<.5$. At $\alpha=M=0$, we have a strong effect of outsourcing on wage 
moderation, which in turn has a large effect on domestic labor because of the initially high employment level. As the share of outsourcing increases, the wage moderating effect decreases, i.e. $w_{M M}>0$ as well as the impact of wage moderation on domestic employment, i.e. $L_{w w}>0$. At $\alpha=(\delta+1)^{-1}$ when $L=\delta M$, direct and indirect effect are of equal size so that in this special case, a further increase in international integration would not affect domestic employment but a further economic integration would then have unambiguously adverse effects on domestic employment in outsourcing firms.

PROPOSITION 2: Increasing economic integration that leads to a fall in the outsourcing cost parameter c will moderate domestic wages set by the union and increase domestic employment in unionized firms that engage in outsourcing as long as the outsourcing share does not exceed the critical value $(\delta+1)^{-1}$.

\section{Effects of labor tax policy}

With the results from the two previous sections, we can start analyzing the impact which labor tax policy has on domestic employment in firms that can outsource a part of its labor activity. Tax policy instruments affect domestic labor costs and the wage formation directly. Moreover, it is important to emphasize that tax policy instruments affect the domestic workforce indirectly via the strategic outsourcing options of the outsourcing firm in stage 3 and therefore the total employment via the induced wage rate change and the direct replacement of domestic workers by foreign workers.

For the strategic outsourcing decisions of the firm, it is straightforward to calculate the following qualitative results (see Appendix 1). First, we have $M_{t}=-\pi_{M t} / \pi_{M M}>0$. In the case of tax exemption, we have $M_{a}=-\pi_{M a} / \pi_{M M}<0$. A higher wage tax increases outsourcing while a higher tax exemption for workers lowers outsourcing. A more general unemployment benefit system, by contrast, makes the 
domestic trade union more demanding thus increasing outsourcing $M_{b}=-\pi_{M b} / \pi_{M M}>0$. All these effects work via their effect on domestic gross wages. If the domestic gross wage rises (decreases), then outsourcing activities cet. par. rise (decrease). Increases in the domestic wage tax or the unemployment benefit payments increase outsourcing because the domestic wage rises, while increases in the wage tax exemption decreases outsourcing because it decreases the domestic wage.

\subsection{How single tax instruments can work on wage formation and employment}

With these partial derivatives we can now derive the total effects the tax policy instruments have on the wage setting by monopolistic trade unions. The total effect consists of the direct wage effect and on the indirect effect via the impact these instruments have on the strategic outsourcing decision of firms and thereby also on the wage rate. For a change in the wage tax rate we obtain,

$$
\frac{d w}{d t}=\underbrace{w_{t}}_{+}+\underbrace{w_{M} M_{t}}_{-}=w_{t}-w_{M} \frac{w_{t}}{w_{M}} A=w_{t}(1-A)>0,
$$

where $A<1$ (see Appendix 1 for details). In the presence of outsourcing the total effect of a wage rate change on the wage setting becomes smaller as we have $w_{M} M_{t}<0$. A wage increase due to an increase in the wage tax makes outsourcing more attractive. This in turn reduces the impact the tax rate has on wage setting and lowers the benefits of a wage increase for the trade union. Analogously, the effect of changes in the tax exemption and the unemployment benefit payments are moderated by the same factor $(1-A)$ so that we have

$$
\frac{d w}{d a}=w_{a}+w_{M} M_{a}=w_{a}(1-A)<0 \quad \text { and }
$$

$$
\frac{d w}{d b}=w_{b}+w_{M} M_{b}=w_{b}(1-A)>0
$$


Now we can determine the total effects of the wage tax and the tax exemption both via the wage effect and via the outsourcing effect on domestic employment. Using (7), we obtain

$$
\frac{d L}{d t}=\underbrace{L_{w}}_{-} \underbrace{\frac{d w}{d t}}_{+}+\underbrace{L_{M}}_{-1} \underbrace{M_{t}}_{+}=L_{w} w_{t}+M_{t}\left[L_{w} w_{M}-1\right]<0 .
$$

From the first equation we can unambiguously sign the employment effect of a wage tax increase. Employment falls when the wage tax rises. The second equation decomposes the effect into the employment effect for a given amount of outsourcing activity $M$ and the effect of a change in the strategic outsourcing. Using equation (8)), we obtain

$$
\frac{d L}{d t}\left\{\begin{array}{l}
< \\
= \\
>
\end{array}\right\} L_{w} w_{t} \text { as } \alpha\left\{\begin{array}{l}
> \\
= \\
<
\end{array}\right\} \frac{1}{\delta+1} .
$$

as a condition for the direct effect of outsourcing. As long as the share of outsourcing in the workforce is relatively small, $\alpha<(\delta+1)^{-1}<.5$, the induced outsourcing leads cet. par. to an increase of domestic labor because, as explained above, the indirect effect via the change in the wage elasticity is stronger as long as the share of outsourcing is small. If the degree of outsourcing relative to domestic labor demand is high enough then the impact of a tax reform will become stronger for any given $\eta$. This is always the case when more than 50 percent of the workforce is working abroad. An analogous argument can be made for the case when the tax exemption or the unemployment benefits changes. Using equation (7) we have

$$
\begin{aligned}
& \frac{d L}{d a}=L_{w} w_{a}+M_{a}\left[L_{w} w_{M}-1\right]>0 \text { and } \\
& \frac{d L}{d b}=L_{w} w_{b}+M_{b}\left[L_{w} w_{M}-1\right]<0 .
\end{aligned}
$$


Employment increases when the tax exemption rises (unemployment benefits fall). In addition, domestic employment is substituted for outsourced labor. The second equation isolates the strategic outsourcing component and it becomes obvious that the magnitude of $\alpha$ (see condition (11)) also determines whether $\frac{d L}{d a}\left\{\begin{array}{l}> \\ = \\ <\end{array}\right\} L_{w} w_{a}$ and $\frac{d L}{d b}\left\{\begin{array}{l}> \\ <\end{array}\right\} L_{w} w_{b}$

To determine how a marginal change in the tax policy measures has an effect on employment in terms of outsourcing costs, we have to calculate $d^{2} L / d t d c, d^{2} L / d t d a$ and $d^{2} L / d b d c$. Formal details are shown in Appendix 1. Here it turns out that we have no unambiguous result. When outsourcing just becomes attractive for the firm, i.e. at $\alpha=M=0$, a marginal reduction of the outsourcing costs that makes outsourcing attractive strengthens the impact tax policy measures have on domestic labor, i.e. we have

$$
\left.\frac{d^{2} L}{d t d c}\right|_{\alpha=0}<0,\left.\frac{d^{2} L}{d a d c}\right|_{\alpha=0}>0, \text { and }\left.\frac{d^{2} L}{d b d c}\right|_{\alpha=0}<0,
$$

because in this case we have a strong effect of outsourcing on wage moderation, which in turn has a large effect on domestic labor because of the initially high employment level. A sufficient (but not necessary) condition for a reduced impact of marginal tax policy changes is that outsourcing is sufficiently important in the sense that $\alpha>(\delta+1)^{-1}$. We thus have a non-monotonic impact of strategic outsourcing on the efficacy of tax policy changes. These results can be summarized in

PROPOSITION 3: In the presence of strategic outsourcing, the qualitative effects of domestic labor market policies on domestic labor demand are the same as in the absence of outsourcing. If the share of outsourcing is sufficiently close to zero, the impact of domestic labor market policy changes on domestic employment in outsourcing firms increases while, when outsourcing activities are sufficiently large, the impact becomes smaller when economic integration increases. 


\subsection{Increasing the degree of tax progression}

It is often argued that increasing tax progression is good for employment. In this section, we reanalyze this question in the presence of outsourcing by looking at a tax reform that increases the degree of tax progression while keeping the average tax burden per worker constant, i.e. this means that we assume

$$
t-\frac{t a}{w}=t^{a}
$$

to be constant. An appropriate and intuitive way to define tax progression is to look at the average tax rate progression $(A R P)$, which is given by the difference between the marginal tax rate $t$ and the average tax rate $t^{a}, A R P \equiv t-t^{a}$. The tax system is progressive if $A R P$ is positive, and tax progression is increased if the difference increases (at a given income level, see Lambert 2001, chapters 7 and 8). The government can raise the degree of tax progression when it increases the wage tax and adjusts the tax exemption upwards such that the average tax burden remains constant. Formally we have, by using equations (7) and (8)

$$
\left.\frac{d a}{d t}\right|_{d t^{a}=0}=\frac{\left(w-a+\frac{t a}{w} \frac{d w}{d t}\right)}{\left(t-\frac{t a}{w} \frac{d w}{d a}\right)}=\frac{\left(w-a+\frac{t a}{w} w_{t}(1-A)\right)}{\left(t-\frac{t a}{w} w_{a}(1-A)\right)}>0 .
$$

First we analyze the total wage effects of this tax reform. If we raise tax progression according to (13), we have $d w=(1-A)\left[w_{t} d t+w_{a} d a\right]$. Dividing by $d a$ and substituting the RHS of (12) for $d a / d t$ gives (see Appendix 2):

$$
\left.\frac{d w}{d t}\right|_{d t^{a}=0}=\frac{(1-A)\left[w_{t}+\frac{(w-a)}{t} w_{a}\right]}{\left[1-\frac{a}{w} w_{a}(1-A)\right]}<0 .
$$


A higher degree of tax progression, keeping the relative tax burden per worker constant, will decrease the wage rate both in the presence and in the absence of outsourcing, but the wage rate change is smaller in the case of strategic outsourcing because $0<A<1$.

Finally, we characterize the employment effects of this tax reform. If we raise tax progression according to (13), we have, using equations (9) and (10),

$$
\begin{aligned}
d L & =\left[L_{w} w_{t}(1-A)+L_{M} M_{t}\right] d t+\left[L_{w} w_{a}(1-A)+L_{M} M_{a}\right] d a \\
& =L_{w}(1-A)\left[w_{t} d t+w_{a} d a\right]-\left[M_{t} d t+M_{a} d a\right]
\end{aligned}
$$

The first term indicates the effect the wage rate change has on domestic employment, the second term indicates the induced outsourcing (recall that we have $L_{M}=-1$ ). Dividing (15) by $d t$ and substituting the RHS of (12) for $d a / d t$ gives after some calculations (see Appendix 3):

$$
\left.\frac{d L}{d t}\right|_{d t^{a}=0}=\underbrace{\left.L_{w} \frac{d w}{d t}\right|_{d t^{a}=0}}_{+}-\underbrace{\left.\frac{d M}{d t}\right|_{d t^{a}=0}}_{-}>0 .
$$

The wage moderating effect increases domestic labor demand, given the level of outsourcing. This effect is represented by the first term. Wage moderation, in addition, also makes it attractive to lower the outsourcing activities and replace outsourced labor by domestic labor. Hence both effects work into the same direction so that tax progression remains good for employment when firms have the opportunity to outsource their workforces. Hence, raising tax progression according to (16) is good for employment.

PROPOSITION 4: In the presence of strategic outsourcing, increasing the degree of tax progression increases domestic employment. 


\section{Flexible outsourcing}

So far we have focused on the case where the firm writes long-term contracts that fix the amount of outsourcing before the trade union sets the wage. Alternatively, the firm may be flexible enough to decide upon the amount of outsourcing activity only after the wage is set by the trade union. ${ }^{9}$ The time sequence for this case is described by Figure 3.

Figure 3: Time sequence of decisions: flexible outsourcing

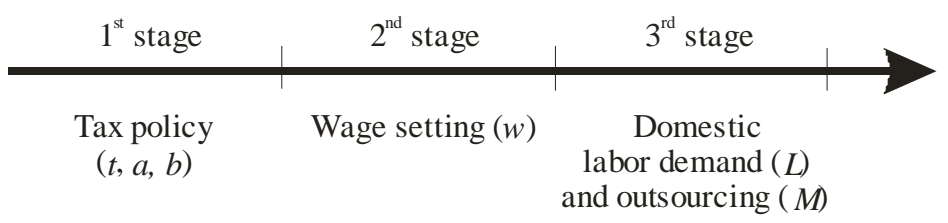

Flexibility implies that the strategic outsourcing aspect disappears. Thus, all equilibrium values of $w, L$, and $M$ differ and this makes it difficult to compare the two equilibrium outcomes directly. We therefore focus on the question to what extent the change in the time sequence affects our qualitative results. In the last stage, the firm maximizes profits with respect to $L$ and $M$. This leads to two standard results. Total employment is set where marginal productivity equals the wage rate. This leads to a demand function similar to equation (2), i.e. we have $L+M=w^{-\delta}$. Since outsourcing is decided after the wage is set, outsourcing has no effect on the wage setting anymore. The profit maximizing outsourcing is thus given by

$$
c M=w,
$$

instead of condition (6) that applies for the case of strategic outsourcing. As a consequence, for any given ratio $M / L$, the wage elasticity becomes larger in this case, i.e.

\footnotetext{
9 See Skaksen (2004) and Braun and Scheffel (2007) who assume that the trade union sets the wage before the firm decides on the degree of outsourcing and the level of production.
} 


$$
-\frac{L_{w} w}{L} \equiv \eta^{f o}=\frac{\delta w^{-\delta}+\frac{w}{c}}{w^{-\delta}-\frac{w}{c}}=\delta\left(1+\frac{M(w)}{L(w)}\right)+\frac{M(w)}{L(w)}=\frac{\delta+\alpha}{1-\alpha} .
$$

where $\alpha=M /(M+L)$. In the second stage the trade union set the wage taking into account the labor demand function as defined by $L=w^{-\delta}-\frac{w}{c}$. Using (18) we obtain

$$
w=\frac{\eta^{f o}}{\left(\eta^{f o}-1\right)} \frac{(b-t a)}{(1-t)} \equiv \frac{\eta^{f o}}{\left(\eta^{f o}-1\right)} \hat{b}=\frac{\delta+\alpha}{\delta+2 \alpha-1} \hat{b} .
$$

As before, we start looking at the impact an increase in international integration $(d c<0)$ has on domestic employment. As is shown in Appendix 4, we obtain a function $d L / d c$ with

$$
\left.\frac{d L}{d c}\right|_{\alpha=0}=-\frac{2 w}{c^{2}(\delta-1)}<0,\left.\frac{d L}{d c}\right|_{\alpha=1}=\frac{1}{2} \frac{w}{c^{2}}>0 \text { and } \frac{d^{2} L}{d c d \alpha}>0 .
$$

As in the case with strategic outsourcing, an increase of economic integration has a positive effect on domestic employment when the share of the outsourced workforce is small but when the share increases it becomes eventually negative. Qualitatively, the results are rather similar to the case of strategic outsourcing but the maximum domestic employment levels differ. At the outsourcing share where domestic employment reaches its maximum (i.e. at $\alpha=(1+\delta)^{-1}$ ) with strategic outsourcing, domestic employment continues to rise as $c$ falls in the case of flexible outsourcing.

The analysis of changes in the wage tax, the tax exemption and the unemployment benefit payments consequently yields similar qualitative results in the case of flexible outsourcing. But the derivatives simplify as we do not have to take into account the feedback effect of the wage tax, the tax exemption and the unemployment benefits payments via outsourcing on employment, i.e. we have

$$
\frac{d L^{f o}}{d t}=L_{w} \frac{d w^{f o}}{d t}=L_{w} w_{t}^{f o}=L_{w} \Delta^{f o} \frac{b-a}{(1-t)^{2}}<0,
$$


and

$$
\frac{d L^{f o}}{d a}=-L_{w} \Delta^{f o} \frac{t}{1-t}>0, \frac{d L^{f o}}{d b}=L_{w} \Delta^{f o} \frac{1}{1-t}<0
$$

with $\Delta^{f_{o}}=\left\lfloor\eta^{f o}-1+\eta_{w}^{f o} w / \eta^{f_{o}}\right\rfloor>0$. Hence the signs of the impact labor market instruments have on employment do not change in the presence of flexible outsourcing. This can be summarized in

PROPOSITION 5: In the presence of flexible outsourcing, the qualitative effects of domestic labor market policies on labour are the same as in the absence of outsourcing but lower in absolute terms.

The analysis of the tax reform that keeps the relative tax burden per worker constant gives us two conditions similar to the conditions (13) and (14), namely:

$$
\begin{aligned}
& \left.\frac{d a}{d t}\right|_{d t^{a}=0}=\frac{\left(w-a+\frac{t a}{w} w_{t}\right)}{\left(t-\frac{t a}{w} w_{a}\right)}>0 . \\
& \left.\frac{d w}{d t}\right|_{d t^{a}=0}=\frac{w_{t}+\frac{(w-a)}{t} w_{a}}{1-\frac{a}{w} w_{a}}<0 .
\end{aligned}
$$

where $\left(w_{t}+\frac{(w-a)}{t} w_{a}\right)^{f o}=-\Delta^{f_{o}}\left[\frac{w(1-t)+t a-b}{(1-t)^{2}}\right]<0$. The increase in tax progression lowers the domestic wage, which in turn increases domestic employment, i.e.

$$
\left.\frac{d L^{f o}}{d t}\right|_{d t^{a}=0}=L_{w} \frac{w_{t}+\frac{(w-a)}{t} w_{a}}{1-\frac{a w_{a}}{w}}>0 .
$$

In qualitative terms, these results for the tax reform are the same as in the case of strategic outsourcing. This can be summarized as 
PROPOSITION 6: Irrespective of whether the firm determines outsourcing before or after the wage is set, increasing the degree of tax progression is always good for domestic employment.

\section{A numerical illustration}

The analytics has shown that, initially, an increase in economic integration followed by an increased outsourcing share has a positive effect on domestic employment because the possibility to outsource moderates wages and this wage moderation effect outweighs the negative impact of outsourcing on domestic employment. The analytics, however, does not allow us to say much about the difference between the two scenarios of strategic and flexible outsourcing. We therefore conducted a numerical simulation of the two equation systems ((7) in the case of strategic outsourcing and A(18), Appendix 4, in the case of flexible outsourcing) for the following parameter values, $b=.8$ and $\delta=3$, the latter providing a cost share of labour equal to $2 / 3$.

In Figure 4 the blue line illustrates how domestic employment and the outsourcing share in the case of strategic outsourcing ( so ) depends on the outsourcing cost parameter $c$. The red lines illustrate respective values for the case of flexible outsourcing ( $f o$ ). As our analytical results have shown, the qualitative results are the same: domestic employment first rises when economic integration increases ( $c$ falls) and only eventually falls when $c$ becomes very small. The maximum domestic output level is reached at lower levels of $c$ when outsourcing is flexible, and so is the absolute level of domestic labour input. The reason is that the impact of flexible outsourcing on labor demand elasticity is stronger than in the case of strategic outsourcing because in the predetermined case, making domestic labor demand more elastic is more costly as the firm has to raise $M$ above marginal cost. 


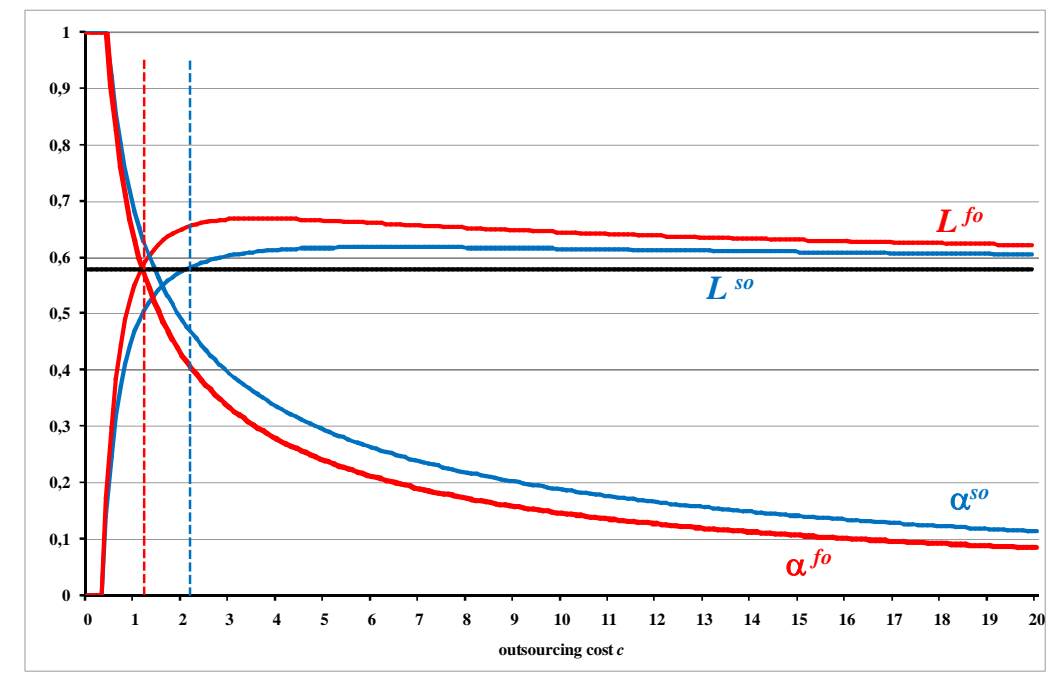

If outsourcing were impossible our numerical simulation model would give us a mark-up of $50 \%$ so that the wage rate would be $\left.w\right|_{c \rightarrow+\infty}=1.2$ and $\left.L\right|_{c \rightarrow+\infty}=0.58$. In Figure 4, the horizontal black line indicates this employment level. It turns out that even for high values of $c$ and thus a small outsourcing share $\alpha$, the wage moderating effect is substantial and so is the effect on domestic employment. For $\alpha=.1$, the wage moderation effect is $6.0 \%$ in the case of strategic outsourcing, which results in $8.5 \%$ more domestic employment. The respective figures for strategic outsourcing are $4.8 \%$ and $4.2 \%$. Only when $c$ becomes sufficiently small, domestic employment eventually falls. In the case of flexible outsourcing, the domestic employment level is higher for all $c>1.6 \cdot b$ or $\alpha<.57$. In the case of strategic outsourcing, this is the case at $c>3 b$ and $\alpha<.44$. These figures, although meant for illustrative purposes only, indicate that in unionized firms outsourcing can have a very strong disciplinary effect on unions that benefit domestic employment. Simulations on the magnitude of tax policy changes indicate that increased economic integration reduces the impact of labor market policy measures in the whole range under consideration so that these result are not reported here. 


\section{Conclusions}

In this paper we have studied the outsourcing decisions of unionized firms for two different scenarios. In the first scenario the firm writes long-term contracts that fix the amount of outsourcing before the trade union sets the wage. In the second scenario, the firm is flexible enough to decide upon the amount of outsourcing activity simultaneously with domestic labor demand decision only after the wage is set by the trade union. We have shown that in both cases outsourcing leads to wage moderation, which is stronger in the case of flexible outsourcing because the outsourcing decision makes the domestic labor demand even more elastic. With long-term contracts the firm will outsource in order to force trade unions to moderate wages to compensate for domestic labor payment.

It turns out that as long as the share of the outsourced workforce is not too large, the induced wage-moderation effect on domestic employment outweighs the direct substitution effect: domestic employment increases in unionized firms within a wide interval of outsourcing costs when outsourcing costs fall so that international economic integration increases. Within our framework we could identify an upper boundary for the outsourcing share. As long as the outsourcing share does not exceed $(\delta-1)^{-1}$, where $\delta$ indicates the total labor demand elasticity, domestic labour increases with outsourcing in unionized firms.

With respect to the impact of labor tax reforms on such firms, the qualitative effects of changes in the wage tax rate, the tax exemption and the unemployment benefit payments are the same as in the absence of outsourcing. Furthermore, increasing the degree of tax progression by keeping the relative tax burden per worker constant continues to be good for employment. Except for very small outsourcing activities, however, the impact of these policy measures on outsourcing unionized firms' domestic employment are diminished when outsourcing costs fall. 


\section{References}

Amiti, M. and S.-J. Wei (2005): Fear of service outsourcing: Is it justified? Economic Policy 20.42, 307-347

Braun, S. and J. Scheffel (2007): A note on the effect of outsourcing on union wages, SFB 649 Discussion Paper 2007-034, Humboldt-Universität zu Berlin.

Egger, H. and P. Egger (2003): Outsourcing and skill-specific employment in a small economy: Austria after the fall of the iron curtain, Oxford Economic Papers, 55, 625643.

Feenstra, R.C. and G.H. Hanson (1999): The impact of outsourcing and high-technology capital on wages: estimates for the United States, 1979-1990, Quarterly Journal of Economics, 114, 907-940.

Görg, H. and A. Hanley (2005): Labor demand effects of international outsourcing: evidence from plant-level data, International Review of Economics and Finance, 14, 365-376.

Hasan, R., D. Mitra and R.V. Ramaswamy (2007): Trade reforms, labor regulations, and labor-demand elasticities: Empirical evidence from India, the Review of Economics and Statistics, 89(3), 466-481.

Hijzen, A., Görg, H. and R.C. Hine (2005): International outsourcing and the skill structure of labour demand in the United Kingdom, the Economic Journal 115, 860878.

Koskela, E. and J. Vilmunen (1996): Tax progression is good for employment in popular models of trade union behaviour, Labour Economics 3, 65-80.

Koskela, E. and R. Schöb (1999): Does the composition of wage and payroll taxes matter under Nash bargaining?, Economics Letters 64, 343-349.

Koskela, E. and R. Schöb (2002a): Why governments should tax mobile capital in the presence of unemployment, Contributions to Economic Analysis \& Policy 1(1).

Koskela, E. and R. Schöb (2002b): Optimal factor income taxation in the presence of unemployment, Journal of Public Economic Theory 4, 387-404.

Lambert, P.J. (2001): The Distribution and Redistribution of Income, $3^{\text {rd }}$ edition, Manchester University Press.

Leahy, D. and C. Montagna (2000): Unionisation and foreign direct investment: challenging conventional wisdom, the Economic Journal, 110, C80-C92.

Musgrave, R.A. and T. Thin (1948): Income tax progression, 1929-1948, Journal of Political Economy 56, 498-514.

Rishi, M. and S. Saxena (2004): Is outsourcing really as bad as it is made sound?, Working Paper, University of Pittsburg.

Senses, M.Z. (2006): The effects of outsourcing on the elasticity of labor demand, CES Discussion Paper, Washington D.C., March.

Sinn, H.-W. (2007): The welfare state and the forces of globalization, CESifo Working Paper No. 1925.

Skaksen, J.R. (2004): International outsourcing when labor markets are unionized, Canadian Journal of Economics, 37, 78-94.

Skaksen, J.R. and J.R. Sörensen (2001): Should trade unions appreciate foreign direct investment, Journal of International Economics, 55, 379-390.

Slaughter, M. (2001): International trade and labor-demand elasticities, Journal of International Economics, 54, 27-56. 
Stefanova, B.M. (2006): The political economy of outsourcing in the European Union and the East-European enlargement, Business and Politics, 2, issue 2.

\section{Appendix 1: wage setting, optimal strategic outsourcing and domestic employment}

Comparative statics with respect to changes in outsourcing from equation (5) yields

$$
d w\left[(\eta-1)+\frac{\eta_{w} w}{\eta}\right]=\frac{-\eta_{M} w}{\eta} d M .
$$

Using $\quad(\eta-1)+\frac{\eta_{w} w}{\eta}=\frac{(\delta-1) L+\delta M}{L}+\frac{\delta M}{L}=\frac{(\delta-1) L+2 \delta M}{L}$ and $\frac{-\eta_{M} w}{\eta}=-\frac{w}{L}$, we obtain

$$
w_{M}=-\frac{w}{[(\delta-1) L+2 \delta M]} \text {. }
$$

Analogously, we obtain

$$
w_{t}=\frac{\delta(L+M)}{[(\delta-1) L+2 \delta M]} \frac{(b-a)}{(1-t)^{2}} \equiv \Delta^{s o} \frac{(b-a)}{(1-t)^{2}}>0, \text { for } b-a>0 \text {, }
$$

$$
w_{a}=-\Delta^{s o} \frac{t}{(1-t)}<0,
$$

$$
w_{b}=\Delta^{s o} \frac{1}{(1-t)}>0
$$

with $\Delta_{M}^{s o}=-(\delta+1) /[(\delta-1) L+2 \delta M]<0$.

The first-order condition for optimal strategic outsourcing can be expressed, by using $-w_{M} L=w L /[(\delta-1) L+2 \delta M]$, as follows $\pi_{M}=\delta w \frac{(L+2 M)}{[(\delta-1) L+2 \delta M]}-c M=0$ (note that we have $L(w, M)$ from equation (2)). The second-order condition is 


$$
\begin{aligned}
\pi_{M M} & =\delta w_{M}\left[\frac{L+2 M}{(\delta-1) L+2 \delta M}\right]-\delta w \frac{2(L+M)}{[(\delta-1) L+2 \delta M]^{2}}-c \\
& =-\delta w \frac{3 L+4 M}{[(\delta-1) L+2 \delta M]^{2}}-c<0 \\
& =-\delta w\left(\frac{3 L+4 M}{[(\delta-1) L+2 \delta M]^{2}}+\frac{1}{M}\left[\frac{L+2 M}{(\delta-1) L+2 \delta M}\right]\right) \\
& =\frac{\delta w_{M}}{M[(\delta-1) L+2 \delta M]}\left(3 L M+4 M^{2}+(\delta-1)\left(L^{2}+2 L M\right)+2 \delta M(L+2 M)\right) \\
& =\frac{\delta w_{M}}{M[(\delta-1) L+2 \delta M]}\left((\delta-1) L^{2}+L M+4 M^{2}+4 \delta L M+4 \delta M^{2}\right)
\end{aligned}
$$

The differentiation of $\pi_{M}$ with respect to domestic wage tax $t$, tax exemption $a$ and unemployment benefit $b$ gives the following results:

(A6)

$$
\begin{aligned}
\pi_{M t} & =\delta w_{t} \frac{(L+2 M)}{[(\delta-1) L+2 \delta M]}+\delta w \frac{2 M}{[(\delta-1) L+2 \delta M]^{2}} L_{w} w_{t} \\
& =\delta w_{t} \frac{[(L+2 M)((\delta-1) L+2 \delta M)-2 M \delta(L+M)]}{[(\delta-1) L+2 \delta M]^{2}} \\
& =\delta w_{t} \frac{\left[(\delta-1) L^{2}+2(\delta-1) M L+2 \delta M^{2}\right]}{[(\delta-1) L+2 \delta M]^{2}}>0 .
\end{aligned}
$$

In a similar way we have

$$
\begin{gathered}
\pi_{M a}=\delta w_{a} \frac{\left[(\delta-1) L^{2}+2(\delta-1) M L+2 \delta M^{2}\right]}{[(\delta-1) L+2 \delta M]^{2}}<0 \\
\pi_{M b}=\delta w_{b} \frac{\left[(\delta-1) L^{2}+2(\delta-1) M L+2 \delta M^{2}\right]}{[(\delta-1) L+2 \delta M]^{2}}>0, \\
\pi_{M c}=-M<0 .
\end{gathered}
$$

Concerning the precise effects of parameters we have in terms of the wage tax

(A7) $M_{t}=-\frac{\delta w_{t}\left[(\delta-1) L^{2}+2(\delta-1) M L+2 \delta M^{2}\right] M}{\delta w_{M}[(\delta-1) L+2 \delta M]\left[(\delta-1) L^{2}+M L+4 M^{2}+4 \delta M L+4 \delta M^{2}\right]}=-\frac{w_{t}}{w_{M}} A>0$ 
and analogously

$$
M_{a}=--\frac{w_{a}}{w_{M}} A<0 \text { and } M_{b}=-\frac{\pi_{M b}}{\pi_{M M}}=-\frac{w_{b}}{w_{M}} A>0 .
$$

with

$$
A \equiv \frac{M\left[(\delta-1) L^{2}+2(\delta-1) M L+2 \delta M^{2}\right]}{[(\delta-1) L+2 \delta M]\left[(\delta-1) L^{2}+M L+4 M^{2}+4 \delta M L+4 \delta M^{2}\right]}<1
$$

Furthermore, we have $M_{c}=-\pi_{M c} / \pi_{M M}<0$.

To determine the impact of increased economic integration on domestic employment, we substitute (8) in (7) and differentiating this with respect to the wage tax gives

$$
\frac{d^{2} L}{d c d t}=\frac{1}{c} \frac{\left(\begin{array}{l}
[\delta-1) L+2 \delta M]\left[2 \delta M M_{t}-L M_{t}-M L_{M} M_{t}-M L_{t}\right]- \\
{\left[\delta M^{2}-L M\right]\left[(\delta-1) L_{M} M_{t}+2 \delta M_{t}+(\delta-1) L_{t}\right]}
\end{array}\right)}{[(\delta-1) L+2 \delta M]^{2}}
$$

The sign is determined by the sign of the numerator. Here we have:

$$
\begin{aligned}
& {[(\delta-1) L+2 \delta M]\left[2 \delta M M_{t}-L M_{t}+M M_{t}-M L_{t}\right]} \\
& -\left[\delta M^{2}-L M\right]\left[-(\delta-1) M_{t}+2 \delta M_{t}+(\delta-1) L_{t}\right]=
\end{aligned}
$$

$$
\begin{aligned}
& M_{t}([(\delta-1) L+2 \delta M][(1+\delta) M+\delta M-L]-[\delta M-L][(1+\delta) M]) \\
& -L_{t} M((\delta-1) L+2 \delta M+(\delta M-L)(\delta-1)= \\
& M_{t}(\delta(L+M)(1+\delta) M+(\delta M-L)[(\delta-1) L+2 \delta M])-L_{t} M(\delta(1+\delta) M) .
\end{aligned}
$$

Since $M_{t}>0,(\delta-1) L+2 \delta M>0$, and $L_{t}<0$ a sufficient, but not necessary condition for $d^{2} L / d t d c>0$, and also for $d^{2} L / d a d c<0$ and $d^{2} L / d b d c>0$ is $\alpha>(\delta+1)^{-1}$. At $M=0$, we obtain $M_{t}\left(-(\delta-1) L^{2}\right)<0$ so that at least for a very small share of outsourcing, tax policy will affect labour demand more when economic integration increases $(d c<0)$. 
Appendix 2: effect of higher tax progression on wage formation under strategic outsourcing

Substituting the RHS of (13) for $d a / d t$ into $d w=(1-A)\left[w_{t} d t+w_{a} d a\right]$ implies

(A11) $\left.\frac{d w}{d t}\right|_{d t^{a}=0}=\frac{\left(w_{t}(1-A) t\left(1-\frac{a w_{a}}{w}(1-A)\right)+w_{a}(w-a)(1-A)+w_{a}(1-A) \frac{t a}{w} w_{t}(1-A)\right)}{t\left[1-\frac{a}{w} w_{a}(1-A)\right]}$,

which gives (14), where the denominator is positive. Concerning $w_{t}+(w-a) t^{-1} w_{a}$ in

(14) we get

$$
\begin{aligned}
w_{t}+\frac{(w-a)}{t} w_{a} & =\frac{1}{\Delta} \frac{\delta(L+M)}{[(\delta-1) L+2 \delta M]} \frac{[b-a-(w-a)(1-t)]}{(1-t)^{2}} \\
& =-\frac{1}{\Delta} \frac{\delta(L+M)}{[(\delta-1) L+2 \delta M]} \frac{w(1-t)+t a-b}{(1-t)^{2}}<0 .
\end{aligned}
$$

Appendix 3: effect of higher tax progression on domestic employment under strategic outsourcing

Substituting the RHS of (11) for $d a / d t$ in (15) after dividing by $d t$ gives by using $L_{M}=-1$

$$
\left.\frac{d L}{d t}\right|_{d t^{a}=0}=L_{w} w_{t}(1-A)\left[w_{t}+\left.w_{a} \frac{d a}{d t}\right|_{d t^{a}=0}\right]-\left[M_{t}+\left.M_{a} \frac{d a}{d t}\right|_{d t^{a}=0}\right] .
$$

where

$$
\left.\frac{d w}{d t}\right|_{d t^{a}=0}=w_{t}+\left.w_{a} \frac{d a}{d t}\right|_{d t^{a}=0}
$$

and, by using $M_{a}=\frac{M_{t} w_{a}}{w_{t}}$ from (A2) and (A3), 


$$
\begin{aligned}
\left.\frac{d M}{d t}\right|_{d t^{a}=0} & =M_{t}+\left.M_{a} \frac{d a}{d t}\right|_{d t^{a}=0}=M_{t}+M_{a} \frac{\left[\frac{w-a}{t}+\frac{a}{w} w_{t}(1-A)\right]}{\left[1-\frac{a w_{a}}{w}(1-A)\right]} \\
& =\left.\frac{M_{t}}{w_{t}} \frac{\left[w_{t}+\frac{(w-a)}{t} w_{a}\right]}{\left[1-\frac{a w_{a}}{w}(1-A)\right]} \frac{M_{t}}{w_{t}(1-A)} \frac{d w}{d t}\right|_{d t^{a}=0}=-\left.\frac{A}{w_{M}(1-A)} \frac{d w}{d t}\right|_{d t^{a}=0}<0 .
\end{aligned}
$$

so that we obtain

$$
\left.\frac{d L}{d t}\right|_{d t^{a}=0}=\left.\left[L_{w}+\frac{A}{w_{M}(1-A)}\right] \frac{d w}{d t}\right|_{d t^{a}=0}>0 .
$$

which can be expressed as (16).

\section{Appendix 4: wage formation and domestic employment under flexible outsourcing}

Equation (19) gives us a function $w(a, b, c, t)$. We then have the comparative statics for $d c$ and $d t$ (A15) $\quad d w\left[\eta^{f o}-1+\frac{\eta_{w}^{f o} w}{\eta^{f o}}\right]^{-1}=-\frac{\eta_{c}^{f o} w}{\eta^{f o}} d c$ and $d w\left[\eta^{f o}-1+\frac{\eta_{w}^{f o} w}{\eta^{f o}}\right]^{-1} \equiv \eta^{f o} \frac{b-a}{(1-t)^{2}} d t$, and in a similar way also both for $d a$ and $d b$. To explicitly determine $d w / d c$ from (19), we have

$$
\begin{aligned}
d w & =\frac{\alpha_{w}(\delta+2 \alpha-1)-2 \alpha_{w}(\delta+\alpha)}{(\delta+2 \alpha-1)^{2}} \hat{b} d w+\frac{\alpha_{c}(\delta+2 \alpha-1)-2 \alpha_{c}(\delta+\alpha)}{(\delta+2 \alpha-1)^{2}} \hat{b} d c \\
& =-\frac{\alpha_{w}(\delta+1)}{(\delta+2 \alpha-1)^{2}} \hat{b} d w-\frac{\alpha_{c}(\delta+1)}{(\delta+2 \alpha-1)^{2}} \hat{b} d c .
\end{aligned}
$$

and thus

$$
d w\left[1+\frac{\alpha_{w}(\delta+1)}{(\delta+2 \alpha-1)^{2}} \hat{b}\right]=-\frac{\alpha_{c}(\delta+1)}{(\delta+2 \alpha-1)^{2}} \hat{b} d c
$$


with, using $M_{w}=c^{-1}>0$,

$$
\begin{gathered}
\alpha_{w}=\alpha(1-\alpha)\left[\frac{M_{w}}{M}-\frac{L_{w}}{L}\right]=\alpha(1-\alpha)\left[\frac{1}{c M}-\frac{L_{w}}{L}\right]=\frac{\alpha(1-\alpha)}{w}\left[1+\eta^{f_{0}}\right]=\frac{\alpha(1+\delta)}{w} . \\
\alpha_{c}=\frac{M_{c}(L+M)-\left(L_{c}+M_{c}\right) M}{(L+M)^{2}}=\frac{M_{c} L-L_{c} M}{(L+M)^{2}}=\frac{M_{c}}{(L+M)}=-\frac{\alpha}{c}<0 .
\end{gathered}
$$

Thus (A16) can be rewritten as $(\Psi>0)$

(A17) $\frac{d w}{d c}\left[(\delta+2 \alpha-1)+\frac{\alpha(1+\delta)^{2}}{(\delta+\alpha)}\right] \equiv \frac{d w}{d c} \Psi^{-1}=\frac{\alpha(\delta+1)}{(\delta+\alpha)} \frac{w}{c} \Leftrightarrow \frac{d w}{d c}=\Psi \frac{\alpha(\delta+1)}{(\delta+\alpha)} \frac{w}{c}$.

The domestic employment effect of an increase in outsourcing cost $c$ is then

$$
\begin{aligned}
\frac{d L}{d c} & =-\left(\delta w^{-\delta-1}+\frac{1}{c}\right) \frac{d w}{d c}+\frac{w}{c^{2}}=-\frac{1}{c}\left(\frac{\delta}{\alpha}+1\right) \frac{d w}{d c}+\frac{w}{c^{2}}=-\frac{1}{c}\left(\frac{\delta+\alpha}{\alpha}\right) \frac{d w}{d c}+\frac{w}{c^{2}} \\
& =-\left(\frac{\delta+\alpha}{\alpha}\right) \Psi \frac{\alpha(\delta+1)}{(\delta+\alpha)} \frac{w}{c^{2}}+\frac{w}{c^{2}}=\frac{w}{c^{2}}(-\Psi(\delta+1)+1) \\
& =\frac{w \Psi}{c^{2}(\delta+\alpha)}\left(-(\delta+1)(\delta+\alpha)+(\delta+2 \alpha-1)(\delta+\alpha)+\alpha(1+\delta)^{2}\right) \\
& =\frac{w \Psi}{c^{2}(\delta+\alpha)}\left(-2(1-\alpha)(\delta+\alpha)+\alpha(1+\delta)^{2}\right)=\frac{w \Psi}{c^{2}(\delta+\alpha)}\left(2 \alpha^{2}+\alpha\left(\delta^{2}+4 \delta-1\right)-2 \delta\right) \\
& =\frac{w\left(2 \alpha^{2}+\alpha\left(\delta^{2}+4 \delta-1\right)-2 \delta\right)}{c^{2}\left((\delta+\alpha)(\delta+2 \alpha-1)+\alpha(1+\delta)^{2}\right)} .
\end{aligned}
$$

Substituting in $\alpha=0$ and $\alpha=1$ yields the first two conditions of (20). Furthermore it is straightforward to show that $d^{2} L / d c d \alpha>0$. 